\title{
The biooxidation of methanol, ethanol and isopropanol by a defined co-culture at elevated temperatures
}

\author{
N. Al-Awadhi, G. Hamer and T. Egli, Zürich
}

\begin{abstract}
The introduction of more imaginative enrichment and isolation procedures has permitted the isolation of pure cultures of thermotolerant methylotrophic bacteria, a group that was previously unknown. One potential application for such bacteria is in the acrobic biotreatment of petrochemical industry wastewaters at elevated temperatures. Here, the growth and biooxidation characteristics of one such bacterium, Bacillus sp. NCIB 12522, in co-culture with a Gram-negative thermophilic non-methylotrophic solvent utilizing bacterium, NA17, on a mixture of methanol, ethanol and isopropanol, under both steady and transient state continuous flow culture conditions are reported. The results indicate that at dilution rates $<0.2 \mathrm{~h}^{-1}$ effective biooxidation can be achieved at temperatures between $50^{\circ}$ and $57^{\circ} \mathrm{C}$. As a result of step increases in bioreactor feed concentrations, the fraction of the methylotroph present in the co-culture changed according to whether the methanol or the ethanol concentrations were increased, but when isopropanol was increased, no change in the methylotroph fraction occurred between the initial and final steady states.
\end{abstract}

\section{Introduction}

Most studies on the biooxidation of industrial effluents fail to define either the component moieties of the mixed process culture responsible or the constituent pollutants present in the effluent stream under examination. To improve upon this and develop a better understanding of process functioning, it is necessary to define both the constituents of the process culture and the key pollutants present in the effluent. With respect to the former, one possible approach involves the reconstitution of defined mixed cultures from individual isolates. However, a danger of reconstitution is the elimination of satellite microbes that do not utilize a primary carbon energy source, but enhance the process capacities of the primary substrate-utilizers. Some of the best known examples of enhancement of overall culture performance concern methanotrophic mixed cultures [1, 2].

In the case of the pollutants present in petrochemical industry effluents, the key component approach is frequently superior to the use of "lumped" parameters for describing the pollutant load. Hamer [3] has pointed out that, unlike municipal sewage, which contains many thousands of differ- ent pollutants, petrochemical industry effluents frequently contain less than 100 compounds, of which less than 10 comprise more than 80 percent of the total pollutant load. Earlier, the key component concept encouraged Wilkinson and Hamer [4] to examine the biooxidation at $26^{\circ} \mathrm{C}$ of a mixture of methanol, phenol, acetone and isopropanol, that was representative of a particular petrochemical industry effluent, by an ill-defined stable enrichment culture comprizing three distinct moieties, not strains, that utilized methanol, phenol and acetone/isopropanol, respectively.

Most investigations concerning the growth of co-cultures have sought to elucidate the various binary, direct and indirect interactions that occur $[5,6]$. Particular emphasis has been placed on competition for single carbon energy substrates and results in domination by one member in continuous flow cultures $[7,8]$. The theory that has been developed to explain competition in continuous cultures [9] is based on an absence of direct microbial interactions. Competition is of primary importance only under operating conditions where selection is occurring, i.e. during transient state operation.

In the case mixed substrate utilization, most investigations are concerned with the growth of pure monocultures on binary substrate mixtures. For batch operation either diauxic [10] or sequential substrate utilization patterns are commonly observed. However, a substrate mixture that exhibited diauxic growth in batch cultures has been shown to be utilized simultaneous by a pure monoculture in a chemostat and such behaviour is probably general [11]. Overall strategies for mixed substrate utilization by microbes have been discussed in detail by Harder and Dijkhuizen [12].

The growth of either defined binary cultures or defined multi-component cultures on defined substrate mixtures has not attracted widespread study. Exceptions are the studies reported by Gottschal et al. [13] and Kuenen and Robertson [14] with ternary cultures comprizing a facultative and an obligate chemolithotrophic sulphur bacterium and a heterotrophic bacterium on mixtures of inorganic and organic substrates, and more relevant to the work reported here, a study 
by Bitzi [15], where the growth of a binary mesophilic co-culture on solvent mixtures in steady state continuous cultures was investigated and a lack of interaction, i.e. neutralism, was observed. In the study by Wilkinson and Hamer [4], concerning both the steady and the transient state behaviour of a stable triple moiety mesophilic mixed culture growing on a four component solvent mixture, a state of negligible direct interaction approaching neutralism was also shown to exist [16].

The present study is concerned with petrochemical industry effluent treatment at elevated temperatures, i.e. $45^{\circ}-$ $60^{\circ} \mathrm{C}$. Selection of such a temperature range for study is based on both requirement, in hot arid regions where petrochemicals manufacture is expanding, for the effective and efficient biotreatment of effluents in the thermotolerant range for microbial growth and on concepts concerning the acceleration of hydrolysis and degradation rates at elevated operating temperatures [17]. In previously reported fundamental studies on potentially suitable process microbes for elevated temperature effluent treatment, thermotolerant methylotrophic bacteria [18] and thermophilic non-methylotrophic, solvent-utilizing bacteria [19] have been isolated and characterized. The growth characteristics of one thermotolerant, methylotrophic strain, Bacillus sp. NCIB 12522, has been extensively investigated both in batch [20] and in continuous flow [21] culture, although only batch culture data are available for non-methylotrophs [19]. Here, results obtained for the above methylotrophic strain growing in continuous flow co-culture with one thermophilic Gramnegative, solvent-utilizing bacterium (NA17) and a mixture of methanol, ethanol and isopropanol as the carbon substrate are reported. A primary objective was to determine whether the reconstituted co-culture, from the same original source, exhibited either summation of the individual characteristics of its components or some alternative, more complex, behavioural pattern.

\section{Materials and methods}

\subsection{Organisms}

The co-culture used comprised two bacteria that were maintained separately; a Bacillus sp. NCIB 12522 which is a thermotolerant restricted facultative methylotroph and was isolated from a technical-scale aerobic thermophilic waste sludge biotreater [18] and a Gram-negative non-methylotrophic solvent-utilizing thermophilic cocco-bacterium, NA 17, which was also isolated from the same source [19]. The Bacillus sp. NCIB 12522 was maintained on methanol agar slopes over $4-5$ months at $4{ }^{\circ} \mathrm{C}$ and working stock cultures were maintained on methanol agar plates incubated at $48^{\circ} \mathrm{C}$. The Gram-negative cocco-bacteria NA 17 was maintained similarly, but with ethanol as the carbon energy source. Of the carbon substrate mixture used in the present experiments, Bacillus sp. NCIB 12522 utilizes only methanol and isopropanol, whilst the cocco-bacterium, NA 17, utilizes only ethanol and isopropanol.

\subsection{Culture medium}

The co-culture was grown in a defined mineral salts medium which contained per $\mathrm{m}^{3}: \mathrm{H}_{3} \mathrm{PO}_{4}\left(85 \%\right.$ solution), $0.1 \mathrm{dm}^{3}$; $\mathrm{K}_{2} \mathrm{SO}_{4}, 0.05 \mathrm{~kg} ; \mathrm{MgSO}_{4} \cdot 7 \mathrm{H}_{2} \mathrm{O}, 0.16 \mathrm{~kg} ; \mathrm{NaCl}, 0.05 \mathrm{~kg}$; $\mathrm{CaCl}_{2} \cdot 2 \mathrm{H}_{2} \mathrm{O}, 0.2 \mathrm{~kg} ;\left(\mathrm{NH}_{4}\right)_{2} \mathrm{SO}_{4}, 0.5 \mathrm{~kg} ;$ EDTA-Na ${ }_{2}$, $0.05 \mathrm{~kg} ; 1 \mathrm{dm}^{3}$ trace element solution, $1 \mathrm{dm}^{3}$ vitamin stock solution as described by Egli et al. [22]. $0.02 \mathrm{~kg} / \mathrm{m}^{3}$ polypropylene glycol was added as an antifoam agent. The trace element solution used comprized per $\mathrm{m}^{3}: \mathrm{FeCl}_{3} \cdot 6 \mathrm{H}_{2} \mathrm{O}$, $12 \mathrm{~kg} ; \mathrm{CuSO}_{4} \cdot 5 \mathrm{H}_{2} \mathrm{O}, 1.6 \mathrm{~kg} ; \mathrm{ZnSO}_{4} \cdot 7 \mathrm{H}_{2} \mathrm{O}, 2.2 \mathrm{~kg}$; $\mathrm{MnSO}_{4} \cdot 4 \mathrm{H}_{2} \mathrm{O}, 1.7 \mathrm{~kg} ; \mathrm{Na}_{2} \mathrm{MoO}_{4} \cdot 2 \mathrm{H}_{2} \mathrm{O}, 0.3 \mathrm{~kg} ; \mathrm{CoCl}_{3}$ - $6 \mathrm{H}_{2} \mathrm{O}, 0.8 \mathrm{~kg} ; \mathrm{H}_{3} \mathrm{BO}_{3}, 0.05 \mathrm{~kg} ; \mathrm{HCl}$ (fuming), $35 \mathrm{dm}^{3}$. The carbon energy source used was a mixture comprizing methanol $0.3 \mathrm{~kg} / \mathrm{m}^{3}$, ethanol $0.3 \mathrm{~kg} / \mathrm{m}^{3}$ and isopropanol $0.3 \mathrm{~kg} / \mathrm{m}^{3}$. The mixture was filter-sterilized. When individual carbon energy sources were required to be added to the medium reservoir, these were also filter-sterilized.

\subsection{Bioreactor}

The bioreactor used was $2.4 \mathrm{dm}^{3}$ total volume (Bioengineering AG, Wald, CH). It was fitted with temperature, impeller speed and $\mathrm{pH}$ control, dissolved oxygen monitoring and both pumped medium inlet and culture overflow weir so as to allow operation in the continuous flow mode. Both the oxygen and the carbon dioxide content of the effluent gas stream from the bioreactor could be measured on line. For all cultivation experiments, the culture $\mathrm{pH}$ was maintained at 6.8 by automatic addition of an equimolar $0.5 \mathrm{~N}$ $\mathrm{NaOH} / \mathrm{KOH}$ mixture. The operating volume of the bioreactor was $1.5 \mathrm{dm}^{3}$, the impeller speed used was $16.7 \mathrm{~s}^{-1}$ and the inlet air flow rate was $35 \mathrm{dm}^{3} / \mathrm{h}$.

\subsection{Steady state continuous cultures}

A batch culture was established initially by inocculating the bioreactor with $50 \mathrm{~cm}^{3}$ of each component $\left(0.2 \mathrm{~kg} / \mathrm{m}^{3}\right.$ dry weight). At the end of the batch cultivation, the bioreactor was switched to continuous flow operation. The dilution rates were increased stepwise from $0.1 \mathrm{~h}^{-1}$ up to $1.2 \mathrm{~h}^{-1}$. Under steady state conditions, for each dilution rate used, the bacterial dry weight concentration, residual methanol, ethanol and isopropanol concentrations, concentration of the products, i.e., acetone and acetaldehyde in the bioreactor, and outlet oxygen and carbon dioxide concentrations in the effluent gas stream, were measured. Cultivation was carried out at both $50^{\circ} \mathrm{C}$ and $57^{\circ} \mathrm{C}$.

\subsection{Transient state continuous cultures}

The bioreactor was operated continuously at $53^{\circ} \mathrm{C}$ and a dilution rate of $0.3 \mathrm{~h}^{-1}$ with the carbon substrate feed specified above. Under steady state operation, three separate step changes in the concentrations of the individual carbon sub- 
strates were imposed, such that the concentration of the individual substrate under investigation in the feed was nearly doubled but concentrations of the other two carbon substrates were maintained constant. The same analyses described above for steady state operation were carried out during each observed transient.

\subsection{Analytical methods}

The optical densities of cultures were measured at $546 \mathrm{~nm}$ using a Uvikon 860 spectro-photometer (Kontron AG, Zürich, $\mathrm{CH}$ ) and dry weights were measured in triplicate on $20 \mathrm{~cm}^{3}$ samples of culture that were filtered through tared $0.22 \mu \mathrm{m}$ Nuclepore filters and were dried overnight at $105^{\circ} \mathrm{C}$ to constant weight. Acetaldehyde, methanol, ethanol, isopropanol and acetone were measured by using a Gas Chromatograph type R1A (Shimadzu Corp., Kyoto, J). The column used was $80 / 120$ carbopack $\mathrm{B} / 6.6 \%$ carbowax $20 \mathrm{M}$, $2 \mathrm{~m} \times 2 \mathrm{~mm}$ i. d. Column temperature was $70^{\circ} \mathrm{C}$ and the flow rate of the carrier gas (nitrogen) was $40 \mathrm{~cm}^{3} / \mathrm{min}$. Oxygen and carbon dioxide concentrations in the effluent gas stream from the bioreactor were measured with a paramagnetic oxygen analyser (Oxymat 3, Siemens AG, D) and an infrared carbon dioxide analyser (Binos 1, Leybold-Heraeus GmbH, Hanau, D), respectively. Rates were then calculated on the basis of an inert gas balance. During transient state operation relative cell numbers were estimated by direct counting of warm air dried samples of culture under a light scatter microscope, fitted with a grided ocular lense, at $1000 \times$ magnification. Differentiation was based on bacterium shape; Gram-negative cells being coccoidal ( $1 \mu \mathrm{m}$ in diameter) and Bacillus sp. NCIB 12522 cells being rods (ca. $2 \mu \mathrm{m}$ in length).

\section{Results}

The steady state operation of the co-culture comprising the thermotolerant methylotrophic Bacillus sp. NCIB 12522 and the thermophilic non-methylotrophic solvent-utilizing bacterium NA 17, with methanol $\left(0.3 \mathrm{~kg} / \mathrm{m}^{3}\right)$, ethanol $(0.3 \mathrm{~kg} /$ $\left.\mathrm{m}^{3}\right)$ and isopropanol $\left(0.3 \mathrm{~kg} / \mathrm{m}^{3}\right)$ as a mixed carbon substrate in the feed to the bioreactor, was studied at $50^{\circ}$ and $57^{\circ} \mathrm{C}$. The former temperature was within the optimum temperature range for growth of both bacteria, whilst the latter was in the superoptimum temperature range for the growth of both bacteria on solvents. The steady state concentrations of the bacterial biomass with respect to dilution rate and residual concentrations of the three carbon substrates supplied to the culture are shown in Figs. 1 and 2. Product formation, specifically acetaldehyde and acetone from the incomplete oxidation of ethanol and isopropanol, respectively, were observed at some operating dilution rates and their concentrations are shown in Fig. 3. The specific oxygen uptake and specific carbon dioxide production rates, together with the respiratory quotients observed are given in Fig. 4. The build up of methanol and isopropanol concentrations at dilution

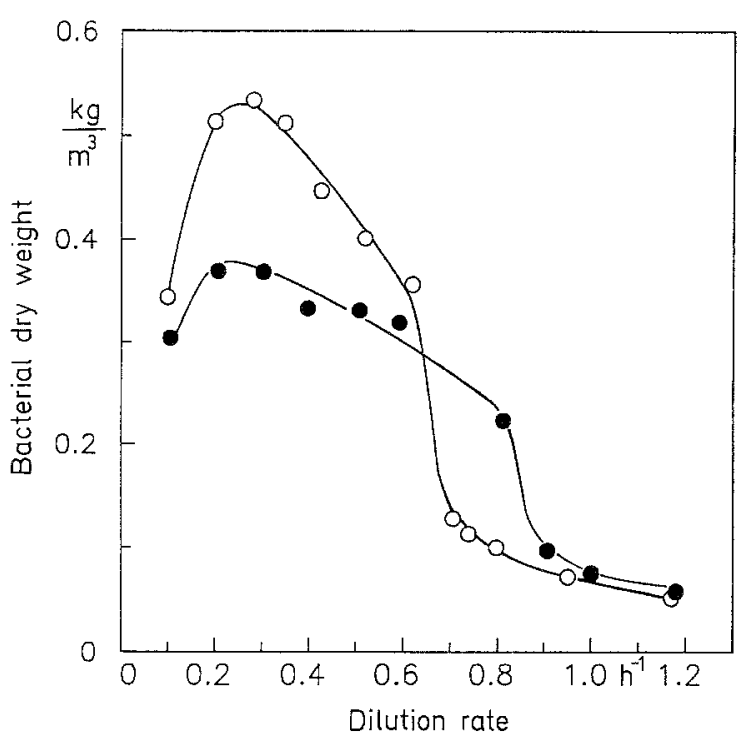

Fig. 1. The effect of dilution rate on the steady state bacterial dry weight; $\circ$ at $50^{\circ} \mathrm{C}$, at $57^{\circ} \mathrm{C}$

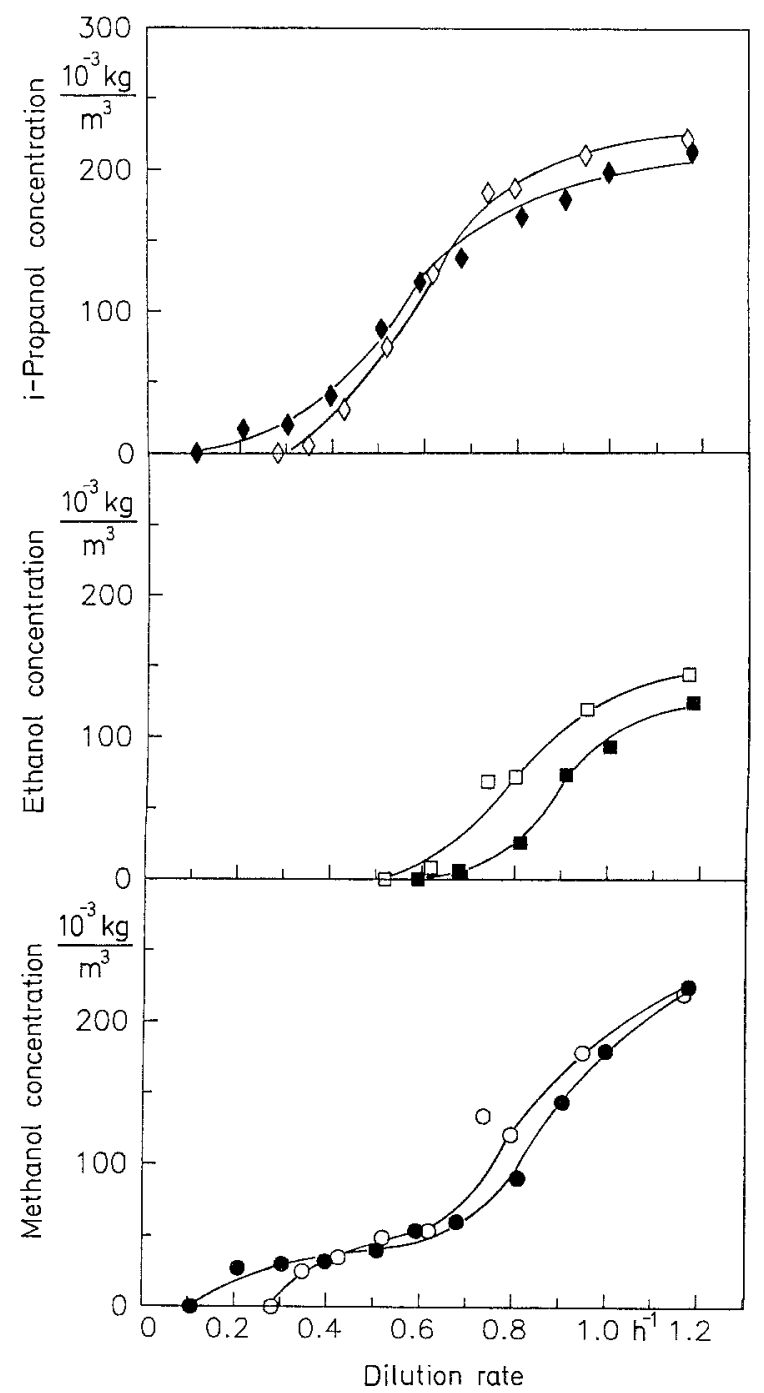

Fig. 2. The effect of dilution rate on the steady state residual carbon substrate concentrations; $O$ at $50^{\circ} \mathrm{C}$, at $57^{\circ} \mathrm{C}$ 


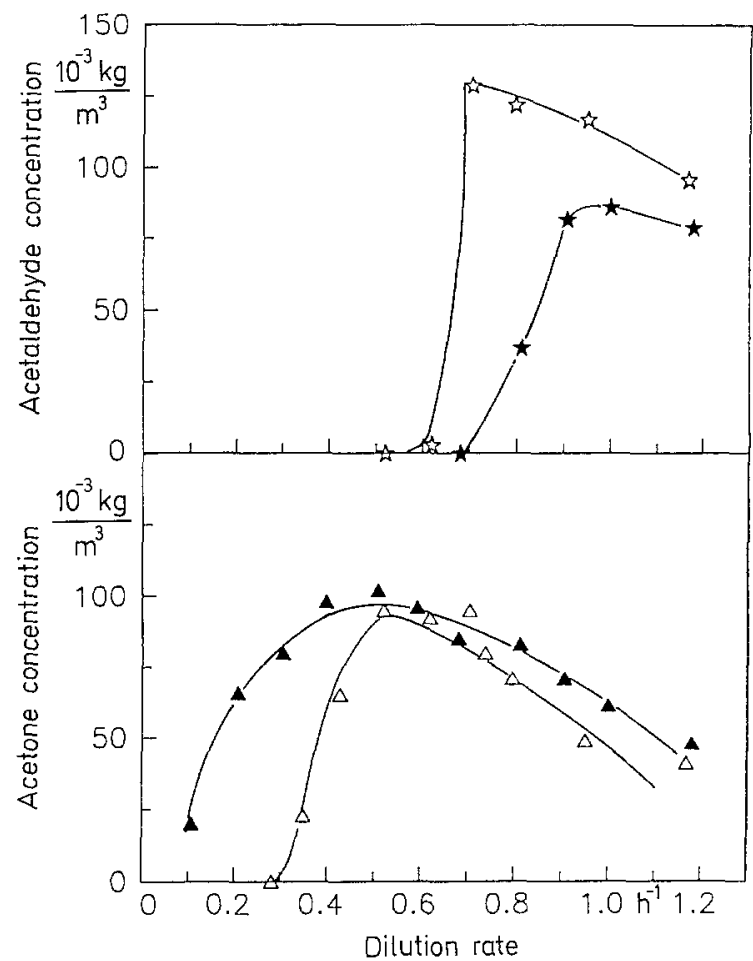

Fig. 3. The effect of dilution rate on product formation; acetone, $\Delta$ at $50^{\circ} \mathrm{C}, \Delta$ at $57^{\circ} \mathrm{C}$, acetaldehyde, si at $50^{\circ} \mathrm{C}$, $\star$ at $57^{\circ} \mathrm{C}$

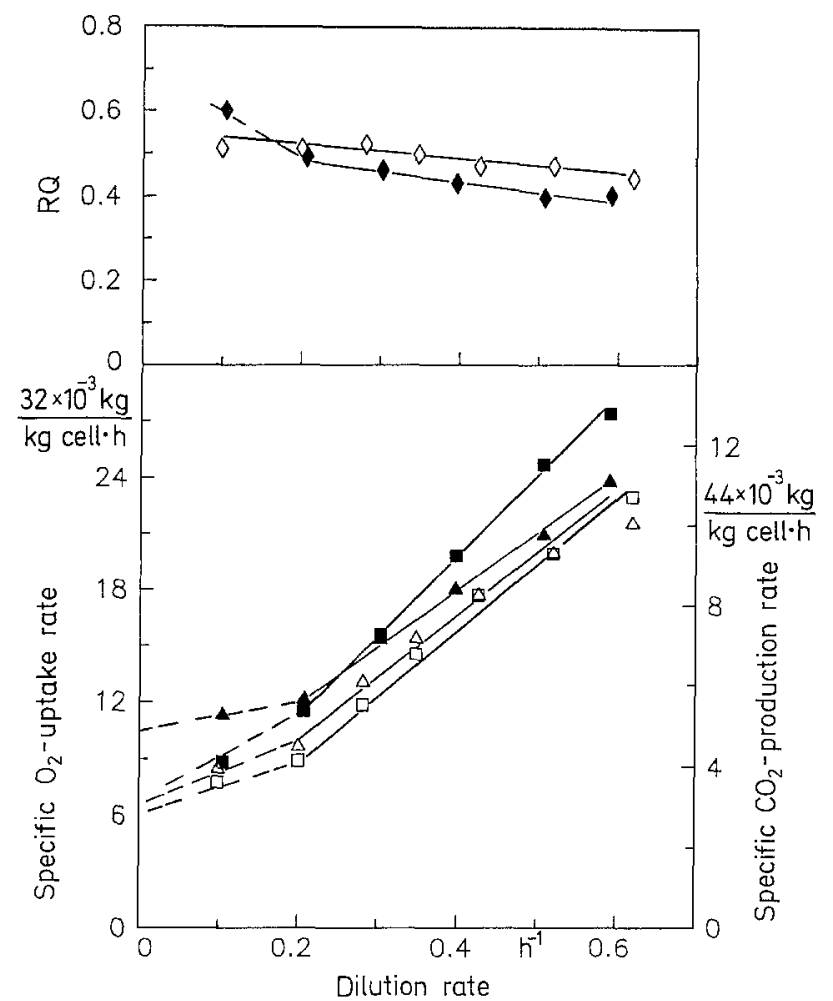

Fig. 4. The effect of dilution rate on the steady state specific oxygen uptake ( $\square$ at $50^{\circ} \mathrm{C}$, at $57^{\circ} \mathrm{C}$ ) and carbon dioxide production rates $\left(\triangle\right.$ at $50^{\circ} \mathrm{C}, \triangle$ at $\left.57^{\circ} \mathrm{C}\right)$ and the respiratory quotient $\left(\diamond\right.$ at $50^{\circ} \mathrm{C}$, at $\left.57^{\circ} \mathrm{C}\right)$ rates above ca. $0.2 \mathrm{~h}^{-1}$ at $57^{\circ} \mathrm{C}$ and above ca. $0.35 \mathrm{~h}^{-1}$ at $50^{\circ} \mathrm{C}$, respectively, and ethanol build up at dilution rates above ca. $0.6 \mathrm{~h}^{-1}$ at both temperatures, resulted in reductions in substrate convertion to biomass. Additionally, the formation of acetone, from isopropanol, and its subsequent utilization and the formation of acetaldehyde, from ethanol, without subsequent utilization impacted on the results.

Because steady state operation is the exception rather than the rule in practice, the effects of step changes in individual carbon substrates were investigated at $53^{\circ} \mathrm{C}$. Prior to making each step change the bioreactor was operated under steady state conditions at a dilution rate of $0.3 \mathrm{~h}^{-1}$ with the carbon substrate feed specified in the preceding paragraph. The strategy adopted for the step changes imposed was to approximately double the concentration of one of the three carbon substrates from $0.3 \mathrm{~kg} / \mathrm{m}^{3}$ to $0.58 \mathrm{~kg} / \mathrm{m}^{3}$ whilst maintaining the concentrations of the other two carbon substrates constant at $0.3 \mathrm{~kg} / \mathrm{m}^{3}$ each.

In the cases of the methanol and the ethanol step increases the resultant transient state behaviour in both the dry bacterial biomass and the residual carbon substrate concentrations are shown in Figs. 5 and 6, respectively. New steady states were attained after ca. 6 and $4 \mathrm{~h}$, respectively. During the transient state behaviour that resulted from the step increase in methanol concentration in the bioreactor feed, a marked peak in methanol concentration in the culture supernatant occurred. However, in the case of ethanol, no such behaviour was observed. In both cases neither products formed nor the concentrations of the residual carbon substrate that were not subject to step increase exceeded their previous steady state concentrations. The fraction of the methylotroph in the co-culture increased from 0.57 to 0.70 as a result of the methanol step increase in the bioreactor feed, whilst in the case of the ethanol step increase its fraction decreased from 0.61 to 0.49 ; a result that is essentially internally consistent.

The corresponding results for the step increase in isopropanol concentration in the bioreactor feed are shown in Fig. 7. In contrast to the previous transient state behaviour, a much more complex response was observed, involving the build up and subsequent utilization of both isopropanol and acetone in the culture supernatant and an elapsed time of ca. $30 \mathrm{~h}$ prior to the establishment of a new steady state. Under the initial steady state conditions, the bacterial dry weight was constant at $0.45 \mathrm{~kg} / \mathrm{m}^{3}$, the residual acetone concentration constant at $7 \cdot 10^{-3} \mathrm{~kg} / \mathrm{m}^{3}$ and the residual isopropanol concentration was essentially zero. Immediately the increased isopropanol concentration entered the continuous co-culture, the bacterial dry weight increased to $0.58 \mathrm{~kg} / \mathrm{m}^{3}$ within $2 \mathrm{~h}$, as a result of acceleration of the growth rate to values significantly higher than the imposed dilution rate, i.e. $0.3 \mathrm{~h}^{-1}$. Throughout the observed transient, neither methanol nor ethanol exceeded their steady state concentration prior to the step increase. In this case, the fraction of the methylotroph in the co-culture under the initial and final steady state conditions remained constant at ca. 0.55. 


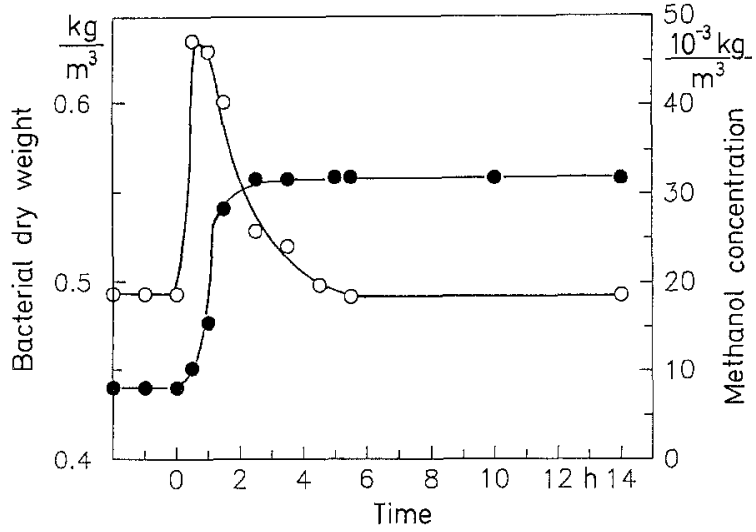

Fig. 5. Dynamic response to a step increase in methanol concentration in the continuous co-culture feed at $53^{\circ} \mathrm{C}$; - bacterial dry weight, $O$ methanol concentration

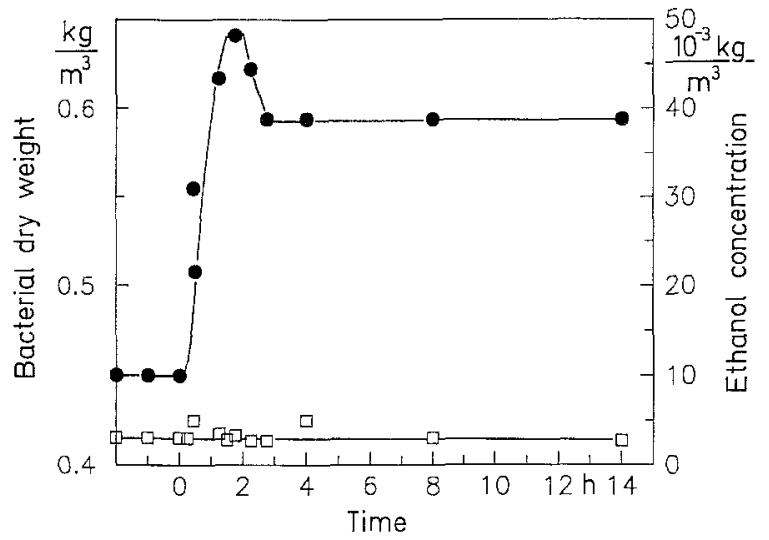

Fig. 6. Dynamic response to step increase in ethanol concentration in the continuous co-culture feed at $53{ }^{\circ} \mathrm{C}$; $\bullet$ bacterial dry weight, $\square$ ethanol concentration

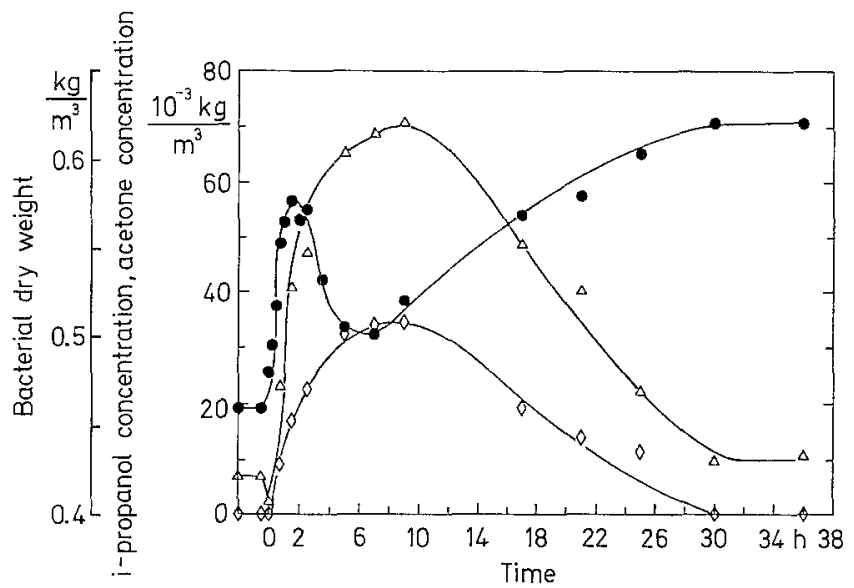

Fig. 7. Dynamic response to step increase in isopropanol concentration in the continuous co-culture feed at $53^{\circ} \mathrm{C}$; $\bullet$ bacterial dry weight, $\Delta$ acetone, $\diamond$ isopropanol

\section{Discussion}

In the present study with the reconstituted, defined, binary thermotolerant/thermophilic co-culture, the observed relationships between the bacterial dry weight and the dilution rate at the two temperatures investigated, shown in Fig. 1, were neither in accordance with typical patterns that have been observed for mono-cultures growing on single carbon substrates nor in accordance with the relationships observed with binary mesophilic co-cultures growing on four component solvent mixtures [15] in completely mixed chemostats. At neither of the temperatures investigated was an extended plateau followed by a precipitous drop when the critical dilution rate value was approached, observed. The only typical feature evident was the decline in bacterial dry weight at low dilution rates $\left(<0.2 \mathrm{~h}^{-1}\right)$, indicating significant intracellular maintenance requirements and extracellular death/ lysis/"cryptic" growth phenomena [23]. Further, the maximum biomass concentrations attained differed markedly, indicating a dramatic effect of temperature on the overall biomass yield coefficient for the co-culture.

The probable explanations for the atypical shapes of the bacterial dry weight versus dilution rate curves shown in Fig. 1, are both the build-up of unutilized substrate in the culture supernatant with increasing dilution rates as is evident from Fig. 2 and changes in overall stoichiometry, involving soluble product formation, as shown in Fig. 3. The former involved a build up of the culture supernatant methanol, ethanol and isopropanol concentrations, resulting in reductions in substrate convertion to biomass. Additionally, the formation of acetone and its subsequent utilization and the formation of acetaldehyde, without subsequent utilization, impacted on the observed results. The dilution rate for initiation and the extents of product formation varied with respect to operating temperature. Both conversion and product formation influence the shapes of the curves in Fig. 1 and together with varying maximum overall biomass yield coefficients affect, the relative shapes of the two curves.

A further factor affecting the shapes of the curves in Fig. 1 was, undoubtedly, the development of wall growth [24]. This occurred when either residual substrates or soluble products built up in the culture supernatant and was markedly more pronounced at $57^{\circ} \mathrm{C}$ than at $50^{\circ} \mathrm{C}$.

The transient behaviour resulting from a step increase in the feed ethanol concentration at a dilution rate of $0.3 \mathrm{~h}^{-1}$ and $53^{\circ} \mathrm{C}$ is typical, with no build up of ethanol in the culture supernatant and only a minor overshoot with respect to the bacterial biomass concentration as shown in Fig. 6 . The new steady state was attained in ca. $2 \mathrm{~h}$. However, the transient behaviour that resulted from step increases in the feed methanol and isopropanol concentrations, shown in Figs. 5 and 7, requires further explanation. In the case of methanol, the biomass equilibrated at its new steady value within $3 \mathrm{~h}$ without overshoot, but during attainment of the new steady state, a distinct peak in the methanol concentration in the culture supernatant was evident. Such behaviour 
has been reported previously for an inhibitory carbon substrate, specifically phenol, supplied as a sole carbon energy substrate for the growth of a mono-culture of a Pseudomonas sp. subjected to a step increase in substrate concentration in the feed [25]. Such a dynamic response to a step increase in the methanol concentration in the continuous culture feed would not have been predicted from the effects of methanol pulses on methanol limited continuous cultures [21] of the thermotolerant methylotroph when formaldehyde accumulation caused washout. However, the response observed can probably be attributed to the marked differences in the concentration of methanol in the supernatant of cultures subjected to a pulse and those subjected to a step increase in the continuous feed concentration.

In the case of the step increase in isopropanol concentration, extended build up and decay patterns were observed for both isopropanol and acetone and can be attributed to the real specific growth rate constant of the culture exceeding the imposed dilution rate, i.e. $0.57 \mathrm{~h}^{-1}$ versus $0.3 \mathrm{~h}^{-1}$. In steady state co-cultures at a dilution rate of $0.57 \mathrm{~h}^{-1}$, acetone and isopropanol accumulation were enhanced. The build up of these two compounds can be assumed to result from similar patterns of behaviour at higher actual growth rates. However, the reduced conversion of isopropanol, to end products was reflected in a subsequent reduction in bacterial dry weight to $0.5 \mathrm{~kg} / \mathrm{m}^{3}, 6 \mathrm{~h}$ after the step increase in isopropanol concentration in the feed. Only then did the bacterial biomass, isopropanol and acetone concentrations start to move towards steady state values. A possible explanation of the observed behaviour could be product inhibition that was subsequently releaved by washout.

The results concerning the methylotroph fraction in the co-culture clearly demonstrated that an increase in the methanol concentration in the bioreactor feed enhanced the fraction of the methylotroph, whilst a corresponding increase in the ethanol concentration in the bioreactor feed resulted in reduction of the fraction of the methylotroph in the coculture, as would be expected on the basis that the methylotroph was incapable of growth on ethanol [18]. However, the unchanged fraction of the methylotroph after a step increase in isopropanol concentration in the bioreactor feed, clearly demonstrated that both the component bacteria of the co-culture utilized isopropanol and/or acetone produced from isopropanol. Earlier, both Bacillus sp. NCIB 12522 and the nonmethylotrophic Gram-negative solvent-utilizing bacterium, NA 17, were shown to grow in pure monoculture on isopropanol $[18,19]$.

The biooxidation of isopropanol is not well understood. Wilkinson and Hamer [4] claimed that its utilization in the presence of acetone involved cometabolism, whilst Taylor et al. [26] showed that the biooxidation of isopropanol involved transformation to acetone as a first step. Bitzi [15] showed that the enzymes involved in the conversion of isopropanol to pyruvate are induced by both isopropanol and acetone. In his bacterium IP, acetone monooxygenase activity was detected and resulted in the oxidation of acetone to acetol. Under stress, the bacterium IP could bypass the sequence of reactions from isopropanol to pyruvate by cleaving acetol, with a ketohydrolase, to form ethanol and methanol. The phenomena observed in the present study under transient state conditions suggest that under such operating conditions, acetone builds up and adversely affects the biooxidation rate of isopropanol, thereby causing it to accumulate in the culture supernatant prior to the establishment of a new steady state. Essentially, a bottle-neck with respect to both isopropanol and acetone, as found in batch cultures of the thermophilic solvent-utilizing bacterium [19], occurred.

\section{Conclusions}

It was clearly demonstrated that mixtures of carbonaceous compounds of the types found as pollutants in petrochemical industry wastewaters can be effectively biooxidized at elevated temperatures $\left(50^{\circ}-57^{\circ} \mathrm{C}\right)$ during continuous operation at dilution rates $<0.2 \mathrm{~h}^{-1}$ by a reconstituted, defined co-culture. However, at dilution rates $>0.2 \mathrm{~h}^{-1}$, both the residual concentrations of carbon substrates and product formation detract from the objectives of effective and complete biodegradable carbonaceous pollutant biooxidation. Further, at low dilution rates, the intra- and extracellular processes that reduce the overall biomass yield coefficient are enhanced and should be exploited, most probably by operating systems with either bacterial biomass recycle or retention as is normal in wastewater biotreatment.

The problems of achieving complete biooxidation of the solvents under transient operating conditions are most probably a result of the limited spectrum of component bacteria present in the culture. Satellite bacteria that are normally encountered in non-defined mixed cultures such as natural enrichment cultures, undoubtedly play an important role in allowing primary substate utilizers to function optimally.

From a fundamental viewpoint, the performance of the co-culture that was observed under both steady and transient state operating conditions was more complex than would have been implied from the individual growth and biooxidation characteristics of the component bacteria.

\section{Acknowledgements}

Our thanks are due to Mrs. R. Meisser for typing the manuscript, Dr. K. Mechsner for the help in cell counting and Mr. P. Schlup for photographic work. One of us (N. Al-A) was the recipient of a Kuwait Institute for Scientific Research (KISR) stipend.

\section{References}

1. Wilkinson, T. G.; Topiwala, H. H.; Hamer, G.: Interactions in a mixed population growing on methane in continuous culture. Biotechnol. Bioengng. 16 (1974) 41-59 
2. Linton, J. D.; Buckee, J. C.: Interactions in a methane-utilizing mixed bacterial culture in chemostat culture. J. Gen. Microbiol. 101 (1977) 219-225

3. Hamer, G.: A biotechnological approach to the treatment of wastewater from petrochemicals manufacture. Instn. Chem. Engrs. Symp. Ser. 77 (1983) 87-101

4. Wilkinson, T. G.; Hamer, G.: The microbial oxidation of mixtures of methanol, phenol, acetone and isopropanol with reference to effluent purification. J. Chem. Technol. Biotechnol. 29 (1979) $56-67$

5. Bungay, H. R.; Bungay, M. L.: Microbial interactions in continuous culture. Adv. Appl. Microbiol. 10 (1968) 269-290

6. Fredrickson, A. G.: Behaviour of mixed cultures of microorganisms. Ann. Rev. Microbiol. 31 (1977) 63-87

7. Harder, W.; Veldkamp, H.: Competition of marine psychrophilic bacteria at low temperatures. Antonie van Leeuwenhoek J. Microbiol. Serol. 37 (1971) 51-63

8. Veldkamp, H.; van Gemerden, H.; Harder, W.; Lannbroek, H. J.: Competition among bacteria: an overview. In Current Perspectives in Microbial Ecology, eds. M. J. Klug \& C. A. Reddy, ASM Washington (1984) 279-290

9. Harder, W.; Kuenen, J. G.; Matin, A.: A review. Microbial selection in continuous cultures. J. Appl. Bacteriol. 43 (1977) $1-24$

10. Monod, J.: Recherches sur la croissance des cultures bactériennes. Paris: Hermann 1942

11. Egli, T.; Bosshard, C.; Hamer, G.: Simultaneous utilization of methanol-glucose mixtures by Hansenula polymorpha in chemostat; influence of dilution rate and mixture composition on utilization pattern. Biotechnol. Bioengng. 28 (1986) 1735-1741

12. Harder, W.; Dijkhuizen, L.: Strategies of mixed substrate utilization in microorganisms. Phil. Trans. Roy. Soc. London B 297 (1982) $459-480$

13. Gottschal, J. C.; de Vries, S.; Kuenen, J. G.: Competition between the facultative chemolithotrophic Thiobacillus A2, an obligately chemolithotrophic Thiobacillus and a heterotrophic Spirillum for inorganic and organic substrates. Arch. Microbiol. 121 (1979) 241-249

14. Kuenen, J. G.; Robertson, L. A.: Interactions between obligately and facultatively chemolithotrophic sulphur bacteria. In: Dean, A. C. R.; Ellwood, D. C.; Evans, C. G. T. (Eds.): Continuous Culture 8. SCI, London/Ellis Horwood, Chichester (1984) $139-158$

15. Bitzi, U.: Abbau organischer Lösungsmittel mit bakteriellen Misch- und Reinkulturen. Diss. ETH Zürich, No. 8118 (1986) $119 \mathrm{pp}$
16. Hamer, G.: Continuous culture kinetics and activated sludge processes. In: Dean, A. C. R.; Ellwood, D. C.; Evans, C. G. T. (Eds.): Continuous Culture 8. SCI, London/Ellis Horwood, Chichester (1984) 169-184

17. Zlokarnik, M.: Bioengineering aspects of aerobic waste water purification. Ger. Chem. Engng. 6 (1983) 183-197

18. Al-Awadhi, N.; Egli, T.; Hamer, G.; Wehrli, E.: Thermotolerant and thermophilic solvent-utilizing methylotrophic, aerobic bacteria. System. Appl. Microbiol. 11 (1989) 207-216

19. Al-Awadhi, N.; Egli, T.; Hamer, G.; Wehrli, E.: Thermophilic solvent-utilizing non-methylotrophic aerobic bacteria. System. Appl. Microbiol. 11 (1989) submitted

20. Al-Awadhi, N.; Egli, T.; Hamer, G.: Growth characteristics of a thermotolerant methylotrophic Bacillus sp. (NCIB 12522) in batch culture. Appl. Microbiol. Biotechnol. 29 (1988) 485-493

21. Al-Awadhi, N.: The characterization and physiology of some thermotolerant and thermophilic solvent-utilizing bacteria. Diss. ETH Zürich, No. 8810 (1989) 195 pp

22. Egli, T.; Weilenmann, H.-U.; El-Banna, T.; Auling, G.: Gramnegative, aerobic nitrilotriacetate-utilizing bacteria from wastewater and soil. System. Appl. Microbiol. 10 (1989) 297-305

23. Hamer, G.: Lysis and "cryptic" growth in wastewater and sludge treatment processes. Acta Biotechnol. 5 (1985) 117-127

24. Topiwala, H. H.; Hamer, G.: Effect of wall growth in steady state continuous cultures. Biotechnol. Bioengng. 13 (1971) 919 922

25. Chi, C. T.; Howell, J. A.: Transient behaviour of a continuous stirred tank biological reactor utilizing phenol as an inhibitory substrate. Biotechnol. Bioengng. 18 (1976) 63-80

26. Taylor, D. G.; Trudgill, P. W.; Cripps, R. E.; Harris, P. R.: The microbial metabolism of acetone. J. Gen. Microbiol. 118 (1980) $159-170$

Received January 26, 1989

Dr. N. Al-Awadhi

Prof. Dr. G. Hamer (corresponding author)

Dr. T. Egli

Institute of Aquatic Sciences

Swiss Federal Institute of Technology Zürich

Ueberlandstrasse 133

CH-8600 Dübendorf

Switzerland 